Using Electronic Flashcards for Student Self-Evaluation of Readiness for Exams

Dr. Kirsten A Davis, Boise State University

Kirsten A. Davis is an Assistant Professor in the Construction Management Department within the College of Engineering at Boise State University. Dr. Davis earned a B.Arch. in Architecture and a B.S. in Civil Engineering from the University of Tennessee, an M.S. in Civil Engineering specializing in Construction Engineering and Management from the University of Colorado, Boulder, and a Ph.D. in Civil Engineering specializing in Construction Engineering and Management from Virginia Polytechnic Institute and State University. Her educational research interests are focused on improving construction management education. 


\title{
Using Electronic Flashcards for Student Self-Evaluation of Readiness for Exams
}

\begin{abstract}
Introductory level courses in many Science, Technology, Engineering, and Math (STEM) disciplines require students to acquire an enormous new discipline-specific vocabulary in preparation for future courses. Students are often not prepared for the amount of self-directed studying they must do to be successful in these types of courses, particularly in their first year of college.

To assist students in more accurately gauging their readiness for an exam, electronic flashcards were implemented in a freshman level Construction Management (CM) materials and methods course, using university provided mobile devices. The flashcards give students a learning aid that they can use to practice their new language with no grade-related consequences. The electronic flashcards provide students an opportunity to self-assess their current level of knowledge, as well as identify where their knowledge may be incorrect or lacking altogether. Construction of accurate self-knowledge is a skill many new college students need assistance to develop. Use of the flashcards may help them improve these skills.

This paper presents preliminary results of the research effort and illustrates the effects of the electronic flashcards. Specifically, this paper evaluates (1) whether the flashcards help students to better prepare for medium and high stakes exams; and (2) whether the flashcards increase the mean exam scores compared to previous semesters with no flashcards.
\end{abstract}

\section{Introduction}

Introductory courses within an academic field of study are often challenging for first-year students. They are often required to acquire a new discipline-specific vocabulary - terminology that will be used throughout their academic and professional career - and they are often not prepared for the amount of self-directed studying they must do to be successful.

Students regularly overestimate their knowledge and abilities ${ }^{1}$. Accurate self-knowledge, defined as the ability to accurately judge one's level of knowledge, is necessary at the college level. Students must be able to recognize what they already know, but more importantly, what they do not know so they can take steps to ensure that their end knowledge meets instructor and course expectations ${ }^{2}$. Some students have this ability when they begin college, but we regularly see students in our classrooms who struggle, particularly in first-year courses, due to inaccurate self-knowledge. An example of this is the student who does not study for an exam because they believe they know the information well enough, yet they receive a $\mathrm{D}$ or $\mathrm{F}$ on the exam.

This research project investigates the introduction of university provided mobile devices into a freshman level construction materials and methods course. Device use is incorporated into the course in several ways, but this paper only examines the use of electronic flashcards, allowing students to study their vocabulary wherever they are. Specifically, this paper provides a preliminary evaluation of: (1) whether the flashcards help students to better prepare for medium 
and high stakes exams; and (2) whether the flashcards increase the mean exam scores compared to previous semesters with no flashcards.

\section{The Course}

This project was carried out with a group of 76 undergraduate students in a 100-level construction management course entitled "Construction Materials and Methods" at Boise State University in the spring and fall semesters of 2012 (32 and 44 students respectively). This course is required for construction management $(\mathrm{CM})$ majors and minors and is a three credit course with 45 hours of classroom instruction. The course introduces students to construction methods and materials used on building projects, with three main objectives:

- Demonstrate knowledge of the methods and equipment commonly used to construct buildings including the foundation and framing systems.

- Identify and discuss the technical aspects of basic building materials such as steel, concrete, masonry, and wood.

- Utilize correct terminology and nomenclature associated with the materials, methods, equipment and building components found on building construction projects.

These objectives are divided into five topical areas for testing purposes: foundations and construction related math, concrete, masonry, steel, and wood and light gauge steel framing.

Of the 32 students enrolled in the course in spring of 2012, 16 had formally declared CM as their major, 5 had declared a CM minor, and 11 were non-majors/minors. In fall of 2012, there were 35 majors, 3 minors, and 6 non-major/minors. Attendance at lectures was mandatory; 89\% attendance was achieved in the spring semester and $92 \%$ in the fall.

The assessments for the course comprised five paper-based exams with multiple-choice, true/false, matching, and short answer type questions (14\% each, with lowest score dropped, for a total of $56 \%$ of course grade), homework ( $8 \%$ of course grade), participation and attendance at lectures ( $6 \%$ of course grade), and a comprehensive paper-based final exam with multiplechoice, true/false, and matching type questions (30\% of course grade). Comprehensive study guides and online study quizzes were made available one week prior to each exam. In each semester, the five regular exams consisted of between 41 and 50 questions with a mean of 44.4 questions and there were 150 questions on the final exam.

\section{The Mobile Devices}

iPod Touch mobile devices were provided to the students free of charge for the spring 2012 semester and iPad 2 mobile devices were provided in fall 2012. In each semester, students were given an orientation that included how to set up the device, how to connect to their university email account, and how to download an app. The students were encouraged to use the device as a personal device, to put their music on it, check their email with it, and otherwise use it as if it were their own. Only a few students were visibly nervous about learning how to use the new device.

By providing the mobile devices to the students, most of the cost issues were avoided. Students were still responsible for paying for any apps, however. This is similar to them being 
responsible for the cost of required textbooks, though all attempts were made to keep the app cost low so as not to create an additional monetary burden on the students. An additional benefit to providing the devices was that all students in the course had the same device, eliminating issues of them having different versions of the device, or having devices that use a different platform (iOS versus Android, for example) where the same app may not be available.

\section{The Flashcards}

The flashcard portion of this research project was developed as a result of the instructor's desire to help students who were struggling in the course, while genuinely attempting to do well. Based on statements from several students, they were studying and making efforts, but were not passing the exams. This project was created to help students better assess their readiness to take an upcoming exam and consequently improve their self-knowledge. It was intended that exam scores, particularly for these struggling students, would increase. Six sets of flashcards were made available for the students to use - one set for each exam.

The Flashcards Deluxe $a p^{3}$ was used for this project. The flashcards were created by the instructor in a Google Docs spreadsheet and were limited to terms and definitions in spring 2012. Images were added to the flashcards for fall 2012. By sharing the file with all of the students in the class, they could easily download the flashcards into the flashcard app. The app is very simple to use and has many options to help the students, including the ability to read the flashcards to the student, create multiple-choice questions to quiz them, and even quiz their spelling of terms.

\section{Data Collection}

To collect data on student use and satisfaction with the flashcards, a brief one-page questionnaire was attached to the back of each student's exam. The questionnaire asked if they had used the flashcards to prepare for that particular exam. If they had used the flashcards, students were asked if they thought it helped them perform better on the exam, why or why not, and what might have been more helpful. If they had not used the flashcards, they were asked why they did not, and whether they thought it would have helped if they had used them. The questionnaire also asked about the amount of study time spent for that exam, along with the student's methods of study, and what grade they expected to receive on the exam.

\section{Results and Discussion}

Altogether, the students were asked to complete the questionnaire six times - once for each exam. The response rate for the questionnaire varied based on the exam, but in the spring semester ranged from a high of $90.3 \%$ (28 of 31 ) to a low of $76.7 \%$ (23 of 30) for an overall response rate of $80.2 \%$ (146 of 182) and in the fall semester ranged from a high of $93.2 \%$ (41 of 44 ) to a low of $72.7 \%$ (32 of 44) for an overall response rate of $81.1 \%$ (214 of 264$)$. Of the students who responded, $74.7 \%$ (109 of 146 total responses) of the spring semester students and $77.1 \%$ (165 of 214 total responses) of the fall semester students self-reported that they used the flashcards. Nearly all responding students thought that they helped (98 of 106 total responses in spring $=92.5 \%$ and 132 of 141 total responses in fall $=93.6 \%$ ). Of those students who reported 
not using the flashcards, a majority (19 of 29 total responses in spring $=65.5 \%$ and 19 of 35 total responses in fall $=54.3 \%$ ) thought that they would have done better on the exam had they used them. Several additional students thought the flashcards might have helped, but were not sure (4 of 29 total responses in spring $=13.8 \%$ and 4 of 35 total responses in fall $=11.4 \%$ ).

Some sample comments from the students regarding why they thought the flashcards helped are listed below:

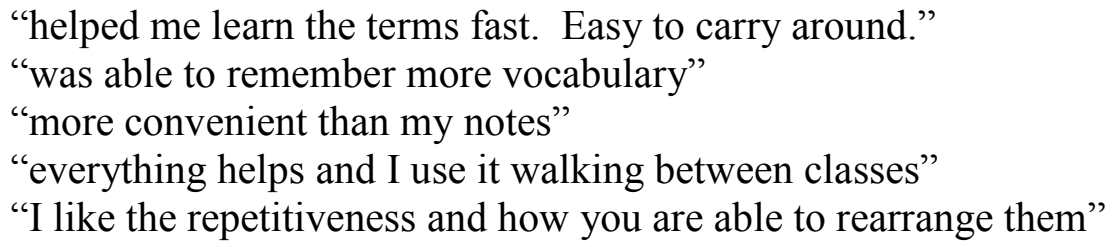

There were very few negative comments regarding the use of the flashcards. In the spring semester, several students commented that the flashcards could be improved by adding pictures to them, so this was done for the fall semester. Two students said they did not have enough money to download the app, which was a little concerning as it only costs $\$ 3.99$, and one student did not download the app because Wi-Fi was not available at home and they kept forgetting to do it on campus. To address any possible financial issues, iPads equipped with the flashcard app were made available for free checkout at the university library.

When studying for the six exams, the spring semester students reported using the flashcards an average of 1.52 hours per exam, which was slightly less than half of their average study time of 3.66 hours per exam. The fall semester students reported using the flashcards more, with an average of 2.30 hours per exam. This was also slightly less than half of their average study time of 4.84 hours per exam.

Table 1 shows the descriptive statistics and 1-tailed Independent t-test for each exam in spring semester 2012 and fall semester 2012, compared with eight previous semesters. A comparison was also made with the combination of spring and fall 2012 scores to see if using flashcards in general improved mean exam scores. Even though students reported using the flashcards and believing that they helped, there was no statistically significant increase for any of the six exams when comparing mean exam scores with those from eight previous semesters. In fact, though not shown in the Table, fall semester 2012 had statistically significant decreases in the mean exam scores for three of the six exams (Test 1, 2, and Final Exam). Spring semester of 2012 did not have this aberration.

While the spring 2012 exam scores did not improve, they also did not decrease. The goal of improvement was not achieved, but students were no worse off. Although mean exam scores would not reflect this, the flashcards may have helped some students do better than they would have otherwise. 
Table 1. Descriptive statistics and 1-tailed Independent t-test table

\begin{tabular}{|c|c|c|c|c|c|}
\hline Test \# & Group & $\mathbf{n}$ & Mean (SD) & t statistic & 1-tailed p \\
\hline \multirow{4}{*}{ Test 1} & 8 past semesters & 300 & $83.01(10.08)$ & \multirow{2}{*}{0.19} & \multirow{2}{*}{0.5750} \\
\hline & Spring 2012 & 31 & 82.65 (11.97) & & \\
\hline & Fall 2012 & 44 & $79.61(13.84)$ & 1.98 & 0.9758 \\
\hline & Spring \& Fall 2012 & 75 & $80.87(13.10)$ & 1.55 & 0.9385 \\
\hline \multirow{4}{*}{ Test 2} & 8 past semesters & 294 & $79.19(11.38)$ & \multirow{2}{*}{0.27} & \multirow{2}{*}{0.6081} \\
\hline & Spring 2012 & 31 & $78.60(12.73)$ & & \\
\hline & Fall 2012 & 44 & $73.65(16.09)$ & 2.84 & 0.9976 \\
\hline & Spring \& Fall 2012 & 75 & $75.69(14.90)$ & 2.22 & 0.9866 \\
\hline \multirow{4}{*}{ Test 3} & 8 past semesters & 285 & $79.81(11.93)$ & \multirow{2}{*}{0.45} & \multirow{2}{*}{0.6740} \\
\hline & Spring 2012 & 30 & $78.77(12.90)$ & & \\
\hline & Fall 2012 & 44 & $78.83(14.03)$ & 0.49 & 0.6893 \\
\hline & Spring \& Fall 2012 & 74 & $78.80(13.50)$ & 0.63 & 0.7347 \\
\hline \multirow{4}{*}{ Test 4} & 8 past semesters & 294 & $81.02(12.14)$ & \multirow{2}{*}{-0.33} & \multirow{2}{*}{0.6281} \\
\hline & Spring 2012 & 30 & $81.78(11.84)$ & & \\
\hline & Fall 2012 & 44 & $81.27(12.47)$ & -0.13 & 0.4497 \\
\hline & Spring \& Fall 2012 & 74 & $81.48(12.14)$ & -0.29 & 0.3865 \\
\hline \multirow{4}{*}{ Test 5} & 8 past semesters & 291 & 77.09 (12.45) & \multirow{2}{*}{-0.47} & \multirow{2}{*}{0.3185} \\
\hline & Spring 2012 & 30 & $78.22(12.21)$ & & \\
\hline & Fall 2012 & 44 & $76.31(12.13)$ & 0.39 & 0.6519 \\
\hline & Spring \& Fall 2012 & 74 & $77.08(12.11)$ & 0.01 & 0.5025 \\
\hline \multirow{4}{*}{$\begin{array}{l}\text { Final } \\
\text { Exam }\end{array}$} & 8 past semesters & 291 & $79.81(9.02)$ & \multirow{2}{*}{-0.11} & \multirow{2}{*}{0.4562} \\
\hline & Spring 2012 & 30 & $80.00(10.96)$ & & \\
\hline & Fall 2012 & 44 & $74.13(12.42)$ & 3.68 & 0.9999 \\
\hline & Spring \& Fall 2012 & 74 & $76.51(12.12)$ & 2.60 & 0.9952 \\
\hline
\end{tabular}

There are several possible explanations for the lack of improvement in exam scores and the notable decreases in the fall semester 2012. First, there is the possibility that the flashcards are not useful and perhaps even detrimental to student learning. While flashcards are not the ideal study tool for every student, it is unlikely that they would cause students to learn less than by not studying at all. It is acknowledged that giving flashcards to the students promotes a more passive study technique than having the students create their own flashcards. Very few students are willing to put in this extra effort though ${ }^{4}$ and by providing them to the students, a level of quality was ensured. Flashcards also promote memorization as a study technique, something the instructor struggles with, as it is important that students understand course material, not just memorize it. 
Another possible explanation for the lack of improvement in exam scores is that the study time with flashcards replaced other study techniques. Perhaps a student chose to use the flashcards instead of reading a textbook chapter or reviewing their notes. With limited study time, students often make choices that may or may not reflect study habits that are the most beneficial for their efforts. Reported average study time per exam for the two semesters with flashcards (3.66 hours in spring 2012 and 4.84 hours in fall 2012) was higher than study times reported for the same course in fall 2010 and spring 2011 where the average study time per exam was 3.10 hours ${ }^{4}$, but more hours of time does not always mean more learning takes place ${ }^{5-7}$.

While both of these explanations are plausible, the lack of decreases in the first semester of flashcard use indicates that they are not the likely explanations. Two other explanations are more probable. It is possible that the fall semester 2012 students had unusually poor selfknowledge and self-regulation (the ability to adjust one's behavior to ensure that acquisition of missing knowledge is successful ${ }^{2}$ ). Test 2 and the Final Exam had the worst means of all ten semesters of the course. Tests were similar in content, format, and level of difficulty and they were all written and graded by the same instructor for all ten semesters. The descriptive statistics (high, mean, low, s.d., median) for each semester have been similar for the comparison semesters (see Table 2 for an example). Spring 2012 has similar characteristics to the comparison semesters, whereas fall 2012 does not, indicating that the flashcards are not likely to be the cause for poor performance in fall 2012. Unusually poor self-knowledge and self-regulation of the fall 2012 students would be a likely explanation for the decreased performance.

Table 2. Descriptive statistics for test 1

\begin{tabular}{|c|c|c|c|c|c|c|}
\hline Semester & \# taken & High score & Mean score & Low score & s.d. & Median score \\
\hline 1 & 32 & 95 & 78.59 & 62 & 8.48 & 79.5 \\
\hline 2 & 28 & 96 & 81.80 & 68 & 6.56 & 82.75 \\
\hline 3 & 58 & 103 & 83.93 & 60 & 9.38 & 85 \\
\hline 4 & 42 & 100 & 80.81 & 56 & 12.51 & 82.5 \\
\hline 5 & 38 & 100 & 83.84 & 50 & 11.28 & 85.5 \\
\hline 6 & 38 & 97 & 85.50 & 69 & 7.30 & 86 \\
\hline 7 & 29 & 103 & 86.45 & 41 & 11.66 & 89 \\
\hline 8 & 35 & 98 & 82.69 & 59 & 10.21 & 85 \\
\hline Spring 2012 & 31 & 100 & 82.65 & 53 & 11.97 & 84 \\
\hline Fall 2012 & 44 & 98 & 79.61 & 34 & 13.85 & 81 \\
\hline
\end{tabular}

A second likely explanation for the decrease in performance in fall 2012 is the iPads themselves. They may have contributed to the poor performance by creating a distraction for students during class (and during study time, as well). In spring 2012, the students had iPod touch devices, which were not often used during class time and no significant change in test grades appeared. In fall 2012, there was some integration of iPad devices into the classroom, giving students a reason to have and use the devices during class time. For many students, this may have been too much of a temptation, allowing them easy access to email, Facebook, YouTube, and other online distractions during class. While giving iPads to students can have many positive outcomes and can be used to increase learning in many ways, iPads can also be a major distracter if used by 
students in non-productive ways and the iPad devices may have contributed to the poor performance on tests in fall 2012.

\section{Conclusions}

Did the flashcards help students better prepare for exams? The students overwhelming felt that they did help. The flashcards received a good deal of use in each semester and were rated favorably on the questionnaires attached to each exam.

Did the flashcards increase mean exam scores? Student performance on exams indicates that the flashcards did not accomplish this goal. However, students did report spending more time studying the course content in the two semesters with flashcards when compared with two previous semesters of self-reported study time for exams ${ }^{4}$.

While the flashcards themselves may not have been a complete success, the larger project of incorporating mobile devices into the construction management classroom holds much promise. Even if significant gains are not found in improving students' self-knowledge and selfregulation, incorporating mobile devices into the classroom is potentially valuable as long as it does not harm the students and does not become a financial burden to them. It allows students the opportunity to incorporate mobile devices into their academic and personal lives, which will likely be a skill they can leverage, both in internships and full-time employment in the construction industry.

\section{Acknowledgements}

This project was supported in part by the Center for Teaching and Learning, Academic Technologies, the Office of Information Technology, and Albertsons Library at Boise State University.

\section{References}

1. Glenberg, A.M., A.C. Wilkinson, and W. Epstein. (1982). "The illusion of knowing: Failure in the selfassessment of comprehension." Memory \& Cognition, 10(6), 597-602.

2. Ibabe, I. and J. Jauregizar. (2010). "Online self-assessment with feedback and metacognitive knowledge." Higher Education, 59(2), 243-258.

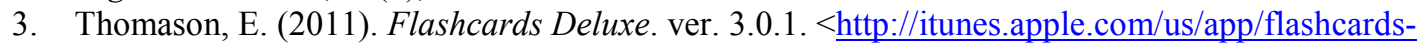
deluxe/id307840670? $\mathrm{mt}=8>$, OrangeOrApple.com,

4. Davis, K.A. (2012). "Study Habits of Students in an Introductory-Level Construction Management Course." 2012 ASEE Annual Conference \& Exposition, San Antonio, TX, USA.

5. Carrier, L.M. (2003). "College Students' Choices of Study Strategies." Perceptual and Motor Skills, 96(1), 5456.

6. Kornell, N. and R.A. Bjork. (2007). "The promise and perils of self-regulated study." Psychonomic Bulletin \& Review, 14(2), 219-224.

7. Gurung, R.A.R. (2005). "How Do Students Really Study (and Does It Matter)?" Teaching of Psychology, 32(4), 239-241. 